Journal of Advanced Research in Fluid Mechanics and Thermal Sciences

\title{
Numerical Investigation for The Valorization of Waste from HMD Cell Using Electrodialysis
}

\author{
Haia M. Elsayd ${ }^{1,2}$, Tamer S. Ahmed $^{1,2}$, Omar E. Abdel-Salam ${ }^{1}$, Moustafa Elshafei ${ }^{3}$, Amr Abdelghany $^{1,{ }^{*}}$ \\ Chemical Engineering Department- Cairo University, Egypt \\ Environmental Engineering program-Zewail City of Science and Technology, Egypt \\ Communication and Information Engineering program-Zewail City of Science and Technology, Egypt
}

\section{ARTICLE INFO}

\section{Article history:}

Received 2 July 2021

Received in revised form 21 August 2021

Accepted 25 August 2021

Available online 17 September 2021

Keywords:

HMD; Electrodialysis; Numerical

investigation; Ion transport

\section{ABSTRACT}

The Hydromagnetic desalination (HMD) system is a continuous process with several advantages, including a high-water recovery ratio, and can be favored economically by producing several industrial byproducts instead of discharging the highly concentrated brine to the environment. In the current work, the ions concentration in the Electrodialysis (ED) technique is simulated using COMSOL Multiphysics V.5.2 software. The ED cell simulated in this paper contains two selective membranes (anion and cation) with a width of $0.25 \mathrm{~mm}$ each. The salt is to be taken away in the middle domain. The cell operation has been simulated to separate the sodium and chlorine ions from the HMD brine waste solution at 40 or $55^{\circ} \mathrm{C}$ temperatures at different voltages and concentrations. In this two-dimensional model, the Nernst-Plank equation has been used to describe ion flux and charge transport in the electrolyte solution. Secondary current distribution theory and the electroneutrality condition have been used in the mathematical model. Finally, Donnan equations have been used to provide the exact fulfillment of boundary conditions for constant voltage mode. The simulation shows that the highest efficiency is obtained at high temperatures and voltage with the lowest feed concentration. Finally, the results have been validated using experimental data from the literature, and a satisfying agreement has been found.

\section{Introduction}

Egypt's annual share of the Nile water decreased by 7 billion cubic meters in 2020 because of the rising populations, water distribution, water resources misuse, inefficient irrigation techniques, rapid economic development in the Nile Basin countries, pollution, and environmental degradation [1]. Moreover, about $85 \%$ of the Nile's water comes from Ethiopia. Currently, Ethiopia is establishing Africa's largest dam, which can cause severe impacts on Egypt. Egypt's water supply from the Nile is anticipated to drop by $25 \%$ over the next seven years. This drop will cause the country to face severe water scarcity soon. Thus, the government focuses on raising awareness of water usage practices,

\footnotetext{
* Corresponding author.

E-mail address: amr.abdelghany@eng1.cu.edu.eg
}

https://doi.org/10.37934/arfmts.87.2.1726 
promoting water conservation, reforming the public water sector, investing in desalination plants, and upgrading irrigation infrastructure [2].

Additionally, there is a growing need in Egypt to explore desalination technologies to meet the need for water and follow other countries in the Middle East that depend on desalination [3]. Over $75 \%$ of the amount of worldwide desalinated water is produced in the Middle East and North Africa (MENA). About $70 \%$ of which is in the Arabian Gulf countries (Saudi Arabia, Kuwait, Qatar, Bahrain, Oman, and the United Arab Emirates) and 6\% is in Libya and Algeria [4].

Desalination is removing dissolved salts from seawater to produce potable water. The desalination process feed can be seawater, brackish water, and inland water [5]. The three most widely used desalination technologies are Reverse Osmosis (RO), Multi-stage Flash (MSF), and MultiEffect Distillation (MED). However, a new technique in the desalination field is called Hydro-magnetic desalination, based on ion separation by electromagnetic forces, which separates the salt in the form of ions from the water stream [6-7]. In this article, the electrodialysis (ED) technique produces valuable chemical products from the HMD process's waste. The electrodialysis process is an electrochemical separation process used to transport salt ions from one solution (through ionexchange membranes) to another solution under electric potential difference. The transport depends on dissolved salts in water that migrate towards electrodes with an opposite electric charge, either positively or negatively charged [7]. In HMD, the potential difference (generated from ions motion under magnetic field) is given by,

$$
E_{m}=B v L
$$

where $B$ is the magnetic field (in Tesla), $v$ is the fluid velocity, and $L$ is the channel width.

The HMD process's waste consists of two brine streams with either a higher concentration of $\mathrm{Na}^{+}$ or $\mathrm{Cl}^{-}$ions [8]. $\mathrm{HCl}$ and $\mathrm{NaOH}$ from waste produced from the $\mathrm{HMD}$ process can be produced during the reaction of $\mathrm{O}_{2}$ and $\mathrm{H}_{2}$ at the anode and cathode, respectively, with the brine. The process requires only cation and anion exchange membranes separating three compartments: one for $\mathrm{HCl}$ production, one for $\mathrm{NaOH}$ production, and one for the circulation of a $\mathrm{NaCl}$ solution between the first two [9]. The anode and middle chambers are separated by an anion exchange membrane (AEM), and the cathode and middle chamber are separated by a cation exchange membrane (CEM) through which a concentrated $\mathrm{NaCl}$ solution is recirculated over the middle compartment. Therefore, $\mathrm{HCl}$ and $\mathrm{NaOH}$ can be produced simultaneously in the anode and cathode chambers [10-11]. In the current work, the ions concentration in the ED technique is simulated using COMSOL Multiphysics V.5.2 software as a preliminary step to produce valuable chemical products from the byproduct streams of the HMD process.

\section{Modeling}

\subsection{Modeling of Electrodialysis}

In multiphysics modeling, physical models in different applications are coupled together for a comprehensive, accurate model. COMSOL Multiphysics is a simulation software designed to provide numerical results from multiphysics modeling [12]. The simulation (when set up professionally) aims to mimic the excessive experimental runs. Multiphysics modeling can provide accurate results; however, the key to successful simulations is to ensure the models' experimental validation. Compared to experimental methods or testing prototypes, modeling allows a robust and costeffective optimization of processes and devices [13]. 
Electrochemical systems with ion-exchange membranes like the electrodialysis process have found wide practical use [14]. For a suitable choice of an operation mode of electro-membrane systems, it is necessary to understand the distribution of electrical potential and concentration over the membrane and adjacent cells [15]. COMSOL Multiphysics V.5.2 software has been used for the simulation and numerical investigation of this system. Nernst-Plank equation was used to describe ion flux and charge transport in the electrolyte solution. Also, secondary current distribution theory and the electroneutrality condition were used as the mathematical model. Finally, Donnan equations were used to provide the exact fulfillment of boundary conditions for constant voltage mode [16-17].

The cell consists of two ions selective membrane; the left is permeable to cations and the right to anions. The middle region is a free-flowing electrolyte region, where salt is to be removed. This region is named the dilute domain. The rightmost domain and leftmost domain are free-flowing electrolyte domains, where the ion concentration increases during cell operation [16]. These domains are called the concentrate domains. In the free electrolyte regions, the flow enters the bottom inlets and exits at the top outlets. Figure 1 is a schematic of this model geometry.

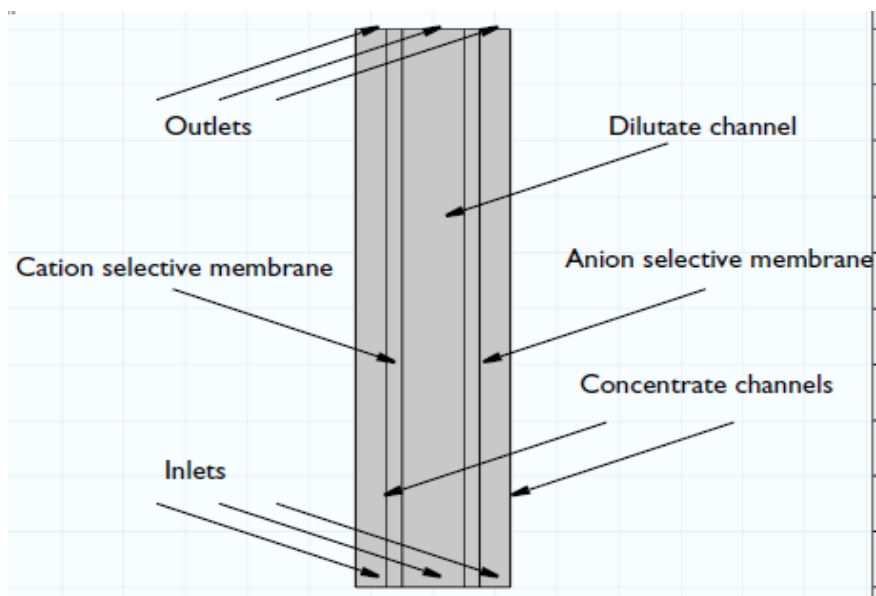

Fig. 1. Schematic for the model geometry

The Nernst-Planck equation is used for ion flux and charges transport as follows:

$$
N_{i}=-D_{i} \nabla C_{i}-Z_{i} u_{m o b, i} i F C i \nabla \emptyset_{i}+C_{i} u
$$

$N_{i}$ : The diffusion, migration, and convection of species I (either $\mathrm{Na}^{+}$or $\mathrm{Cl}^{-}$ions).

$D_{i}$ : is the diffusion coefficient (SI unit: $\mathrm{m}^{2} / \mathrm{s}$ ).

The Migration term consists of the species charge number $Z_{i}$, the species mobility $u_{m o b, i}(s \cdot \mathrm{mol} / \mathrm{kg})$, and the electrolyte potential $(\varphi)$. The convection term denotes the fluid velocity vector $(\mathrm{m} / \mathrm{s})$. The electrolyte current density is calculated using Faraday's law, summing up the molar fluxes' contributions, multiplied by the species charges. The conservation of current is then used to calculate the electrolyte potential [16].

$$
i_{l}=F \sum_{i=1}^{n} z_{i}\left(-D_{i} \nabla c_{i}-z_{i} u_{m, i} F c_{i} \nabla \emptyset_{l}\right.
$$




$$
\nabla . i_{l}=F \sum_{i=1}^{n}\left(\mathrm{z}_{i} \mathrm{R}_{i}\right)
$$

$\mathrm{R}_{i}$ : The reaction sources due to the porous electrode reactions.

Tertiary Current Distribution is used in the electrodialysis module, Nernst-Planck interface solving the electrolyte potential in the free electrolyte and ion-selective membrane domains. In the free electrolyte domains, the ions present are $\mathrm{Na}^{+}$and $\mathrm{Cl}^{-}$The ion-selective membranes also contain additional ions fixed in a matrix. Therefore, the fixed space charge is added while calculating the sum of charges in the electroneutrality condition [16].

$$
\rho_{f i x}+F \sum_{i=1}^{n}\left(z_{i} c_{i}\right)=0
$$

The selective membrane domains do allow for the transport of both $\mathrm{Na}^{+}$and $\mathrm{Cl}^{-}$. The anion exchange membrane transports anions while the cation exchange membrane transports the cations. The fixed membrane charge sign is positive in the anion and negative in the cation exchange membrane domains [4]. The boundary conditions at the boundaries between the membrane and free electrolyte domains are:

- The typical electrolyte current density is equal to the current density in the membrane [16],

$$
n \cdot i_{l, e}=n \cdot i_{l, m}
$$

- The ion flux for each species is continuous over the membrane-free electrolyte interface,

$$
n \cdot N_{i, e}=n \cdot N_{i, m}
$$

- The relation between the potentials and the concentrations is,

$$
\emptyset_{l, m}=\emptyset_{l, e}-\frac{R T}{Z_{i} F} \ln \left(\frac{c_{i, m}}{c_{i, e}}\right)
$$

where $\left(c_{i, m}\right)$ is the species concentration in the membrane, and $\left(c_{i, e}\right)$ is the species concentration in the free electrolyte and $\left(z_{i}\right)$ is the corresponding charge.

\section{Results}

The model is used to separate positive and negative ions to produce chemical products such as $\mathrm{HCl}$ and $\mathrm{NaOH}$. The parameters in Table 1 were used for the calculations. 


\section{Table 1}

Parameters used in the simulation calculations

\begin{tabular}{llll}
\hline Name & Expression & Value & Description \\
\hline $\mathrm{V}_{\text {tot }}$ & $1[\mathrm{~V}]$ & $1 \mathrm{~V}$ & Total potential drop over unit cell \\
$\mathrm{D}_{\mathrm{Na}}$ & $1.334 \mathrm{e}^{-9}\left[\mathrm{~m}^{\wedge} 2 / \mathrm{s}\right]$ & $1.334 \mathrm{E}^{-} 9 \mathrm{~m}^{2} / \mathrm{s}$ & Diffusion coefficient, Na \\
$\mathrm{D}_{\mathrm{Cl}}$ & $2.032 \mathrm{e}^{-9}\left[\mathrm{~m}^{\wedge} 2 / \mathrm{s}\right]$ & $2.032 \mathrm{E}^{-9} \mathrm{~m}^{2} / \mathrm{s}$ & Diffusion coefficient, $\mathrm{Cl}$ \\
$\mathrm{T}$ & $298.15[\mathrm{k}]$ & $298.15 \mathrm{~K}$ & Temperature \\
CCI_o & $0.5\left[\mathrm{~mol} / \mathrm{dm}^{\wedge} 3\right]$ & $500 \mathrm{~mol} / \mathrm{m}^{3}$ & Inlet concentration, $\mathrm{Cl}$ \\
CCMem & $1\left[\mathrm{~mol} / \mathrm{dm}^{\wedge} 3\right]$ & $1000 \mathrm{~mol} / \mathrm{m}^{3}$ & Membrane charge concentration \\
V_avg & $0.005[\mathrm{~m} / \mathrm{s}]$ & $0.005 \mathrm{~m} / \mathrm{s}$ & Channel average flow velocity \\
L & $0.01[\mathrm{~m}]$ & $0.01 \mathrm{~m}$ & Cell length \\
W_ch & $1[\mathrm{~mm}]$ & $0.001 \mathrm{~m}$ & Channel width \\
W_m & $0.25[\mathrm{~mm}]$ & $2.5 \mathrm{E}^{-4} \mathrm{~m}$ & Membrane width \\
\hline
\end{tabular}

Schematic representation of the two-dimensional model is shown in Figure 2 as a set of rectangles. The cell contains two ion-selective membrane domains; the left is assumed to be permeable to cations only while the right to anions only. The middle domain is a free-flowing electrolyte domain, where salt is to be removed. The rightmost and leftmost domains are freeflowing electrolyte domains, where the ion concentration increases during cell operation. Cell length was $0.01 \mathrm{~m}$, channel width was $1 \mathrm{~mm}$, while membrane width was $0.25 \mathrm{~mm}$.

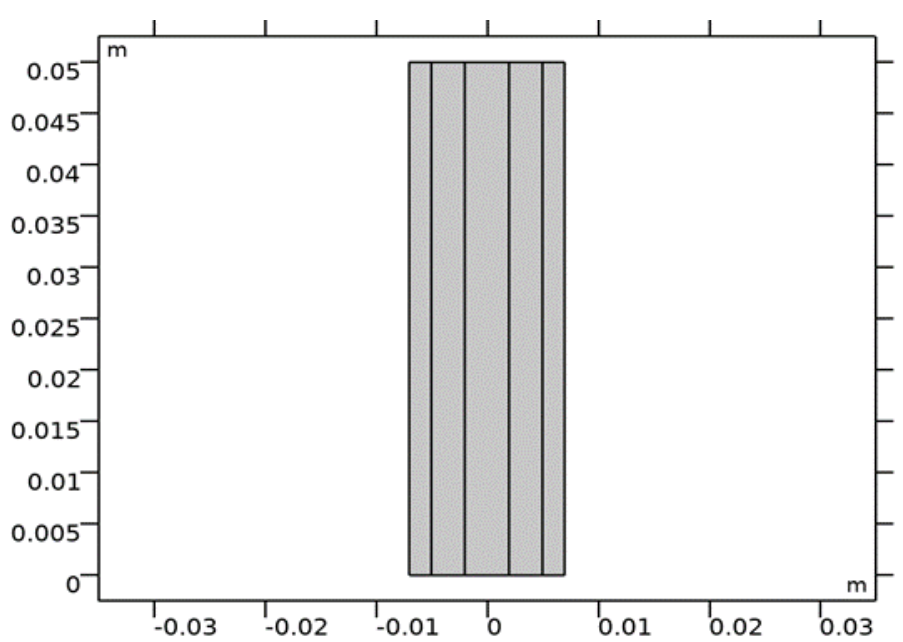

Fig. 2. Schematic representation of the two-dimensional model

A mapped mesh of 18000 elements shown in Figure 3 was used for accurate numerical results of the model and fair distribution to obtain thinner elements in the free electrolyte close to the membrane surfaces. Figure 4 shows the ion concentration in the cell. The concentration increases in the concentrate chamber and decreases in the dilute chamber. Close to the membrane's surface, a boundary layer with a high concentration was formed. 


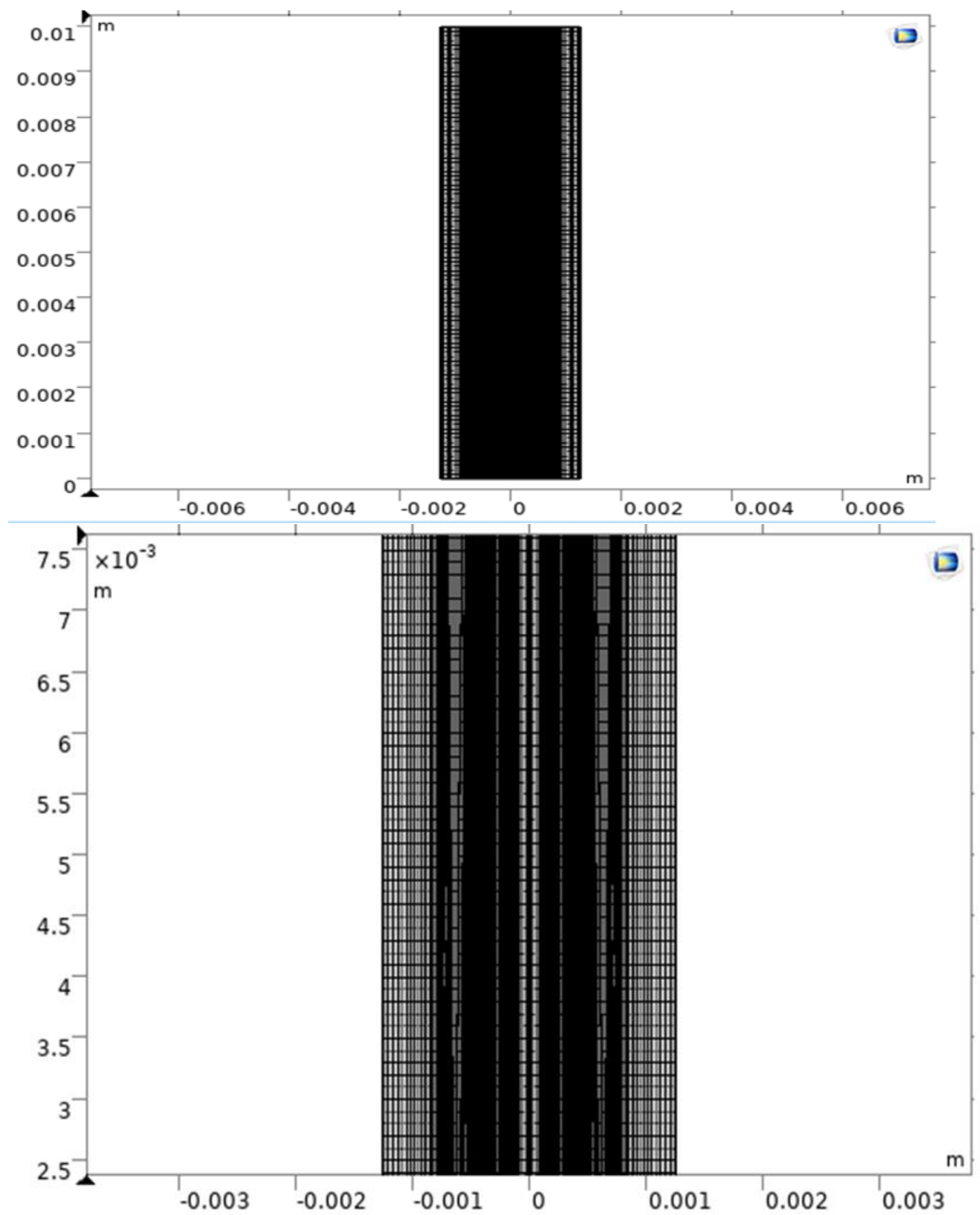

Fig. 3. Schematic diagram of the mapped mesh where dark areas have high density

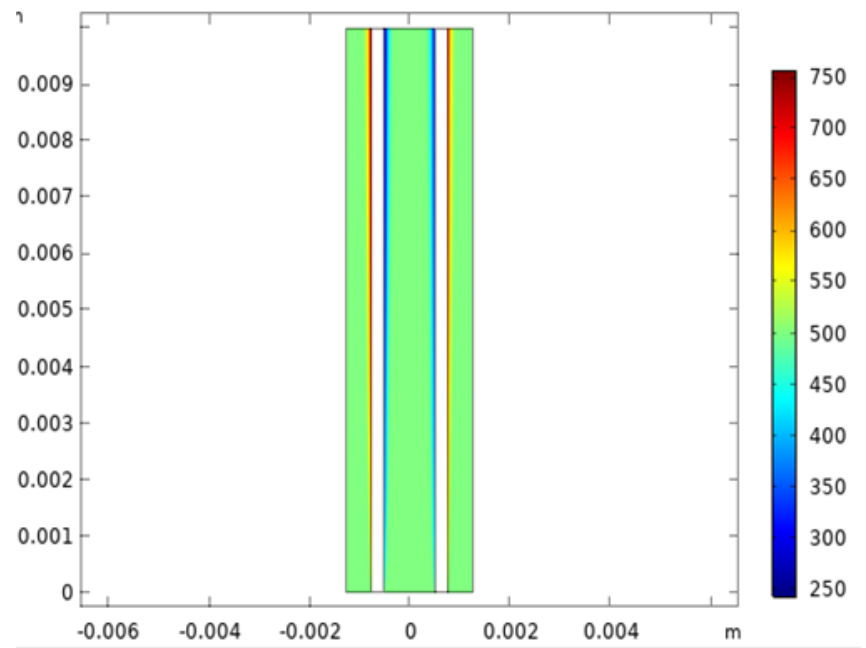

Fig. 4. Concentration distribution 
Figure 5 shows the potential electrolyte distribution of the potential losses that occur in the membranes. The Donnan potential can be seen at the boundaries between the free electrolyte and membrane interface.

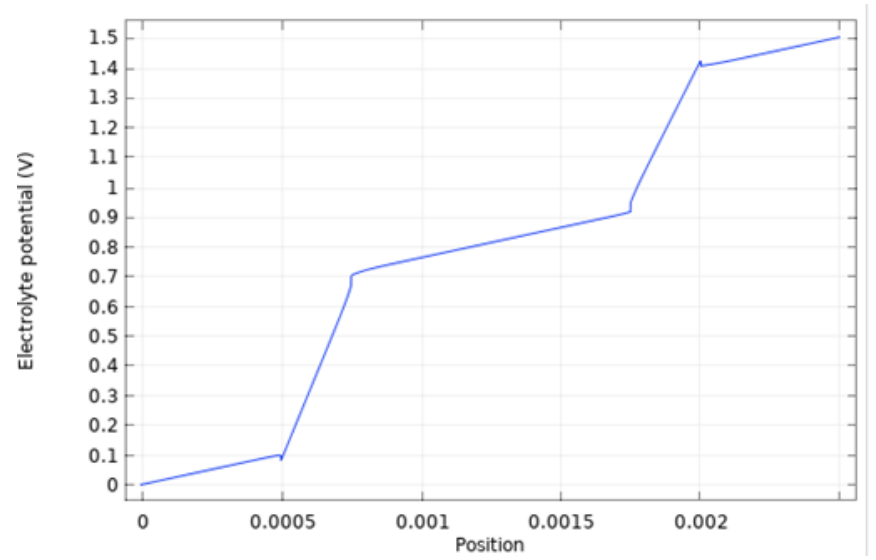

Fig. 5. Electrolyte potential distribution

Figure 6-8 show the ion concentration for different unit cell voltages $0.5,1$, and $1.5 \mathrm{~V}$. The concentration increases with higher potentials. Increasing the voltage increases the driving force, which leads to an increase in the separation.

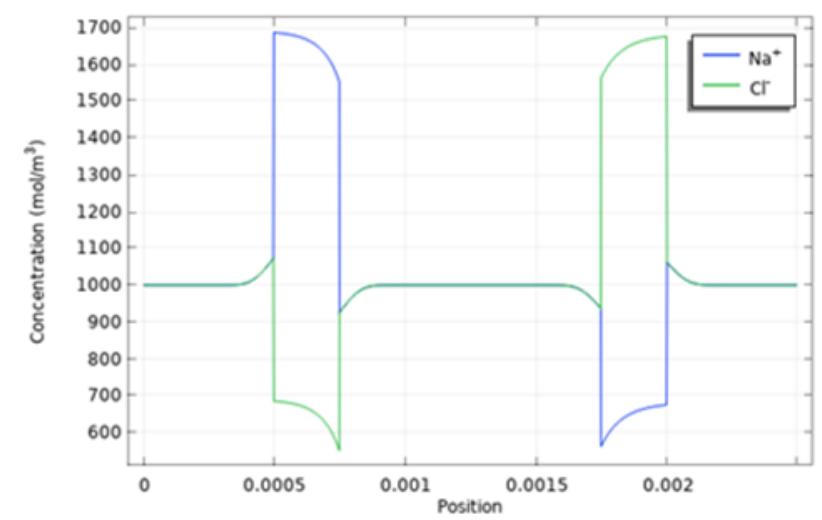

Fig. 6. Ion concentration for 0.5 volt

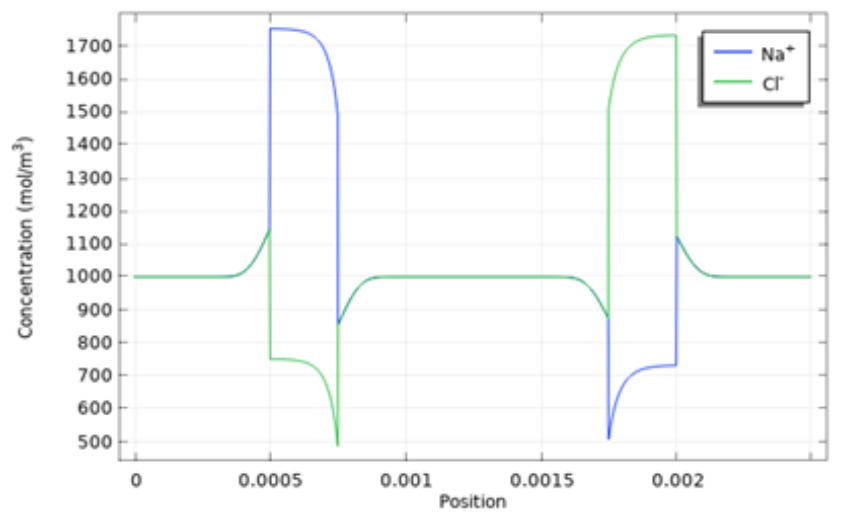

Fig.7. Ion concentration for 1 volt

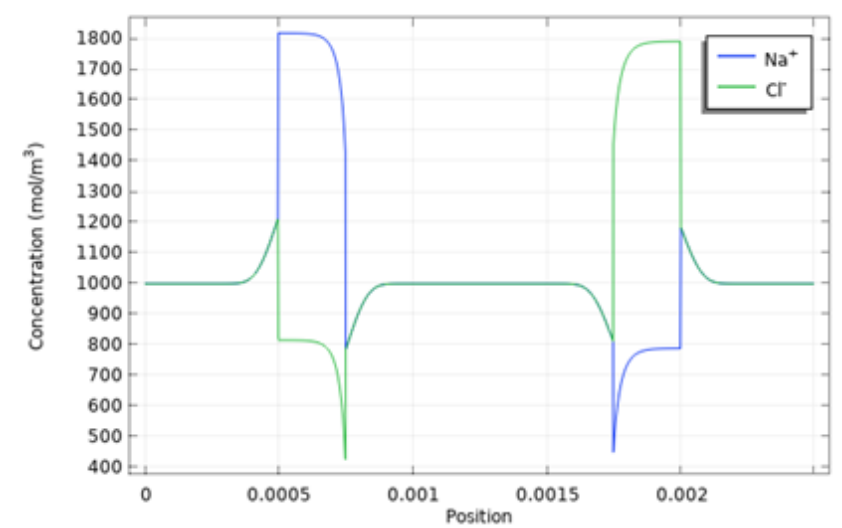

Fig. 8. Ion concentration for 1.5 volt

Figure 9 and 10 show the diffusive fluxes in the free electrolyte for $\mathrm{Cl}^{-}$and $\mathrm{Na}^{+}$, respectively. The diffusive fluxes are prominent close to the membrane boundaries because of high concentration and the migrative fluxes that govern the channels. Finally, Figure 11 and 12 show the validation between 
experimental results from the literature [13] and simulation results at $40^{\circ} \mathrm{C}$ and $55^{\circ} \mathrm{C}$, respectively. Future studies on the effect of gas emission (if $\mathrm{Cl}_{2}$ gas is generated) on the brine solution may be conducted similar to studies by Rahman and Dzulkarnain [18].

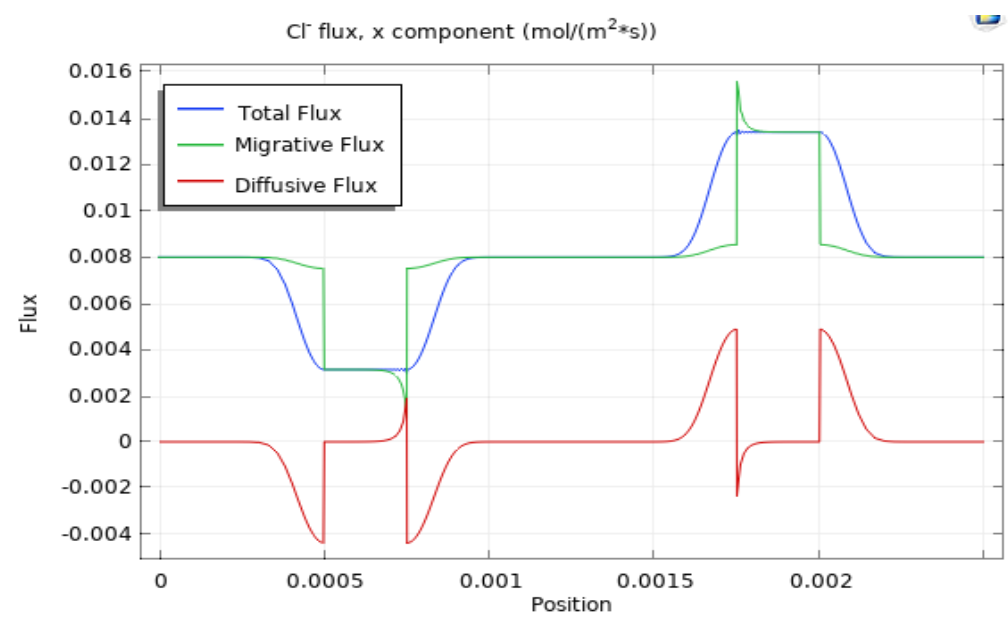

Fig. 9. Diffusive fluxes in the free electrolyte for $\mathrm{Cl}^{-}$

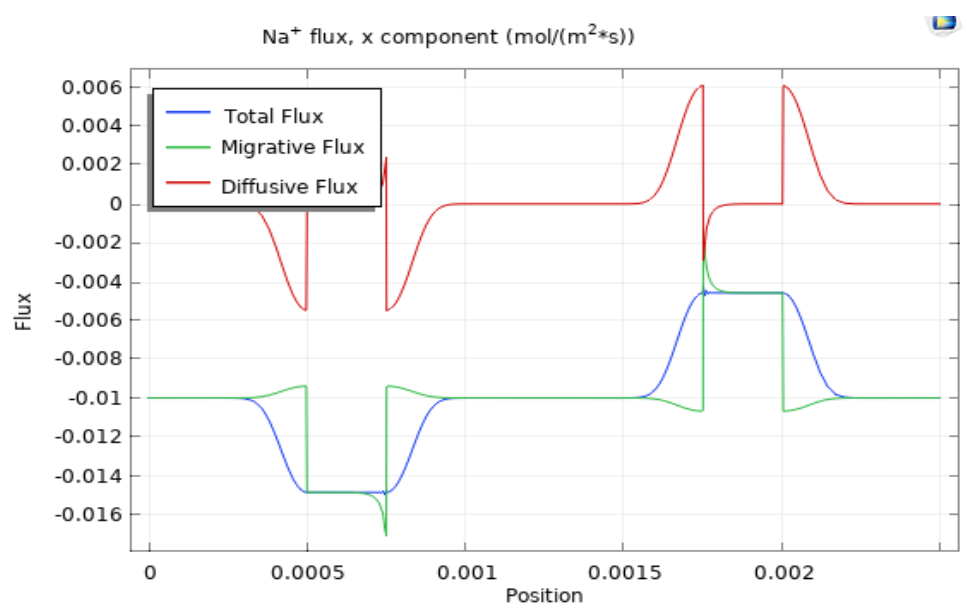

Fig. 10. Diffusive fluxes in the free electrolyte for $\mathrm{Na}^{+}$

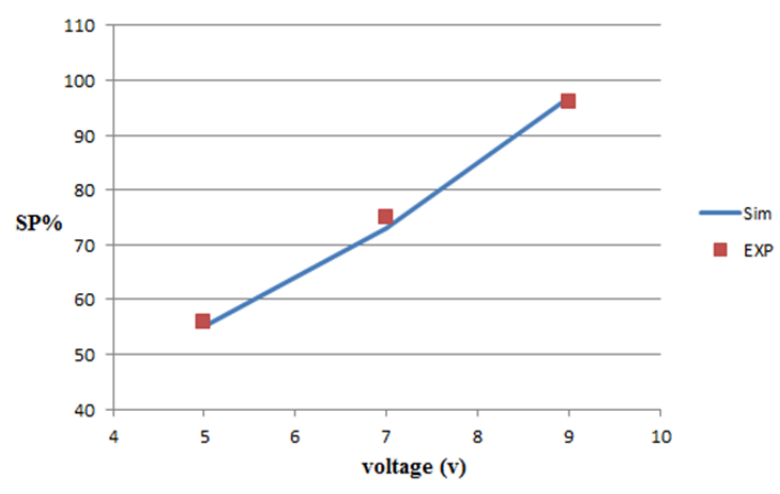

Fig. 11. Validation results at $55 \circ \mathrm{C}$

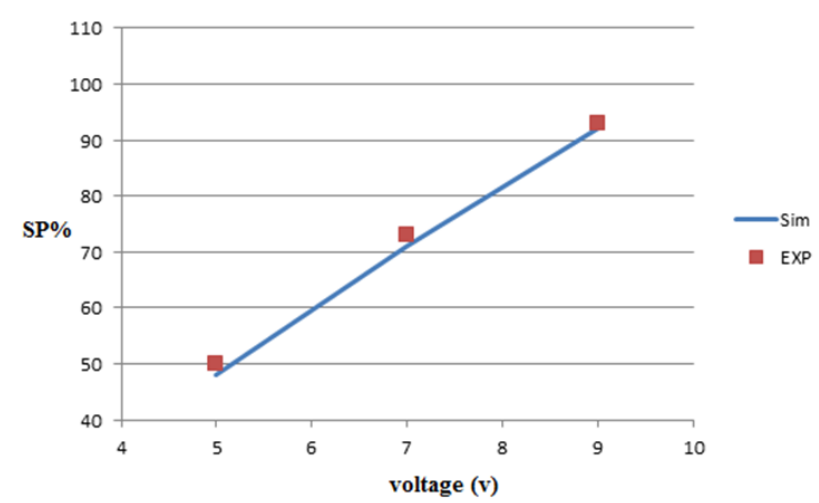

Fig. 12. Validation results at $40 \circ \mathrm{C}$ 


\section{Conclusions}

Our model is used to separate positive and negative ions to produce chemical products such as $\mathrm{HCl}$ and $\mathrm{NaOH}$. A two-dimensional model of a rectangular electrodialysis desalination cell was developed. A mapped mesh of 18000 elements was used for accurate numerical results of the model and fair distribution to obtain thinner elements in the free electrolyte close to the membrane surfaces. The concentration increases in the concentrate chamber and decreases in the dilute chamber. Close to the membrane's surface, a boundary layer with a high concentration was formed. The concentration increases with higher potentials. Increasing the voltage increases the driving force, and this, in turn, leads to an increase in the separation. The diffusive fluxes are prominent close to the membrane boundaries because of high concentration and the migrative fluxes that govern the channels. The modeling results were compared with the experimental values, which indicated that the simulation has acceptable accuracy.

\section{Acknowledgement}

This work is funded by the Egyptian Science and Technology Development Fund (STDF) under grant number 34842.

\section{References}

[1] Dakkak, Amir. "Egypt's Water Crisis-Recipe for Disaster." Retrieved February 26 (2014): 2016.

[2] T. Baconi, "The end is Nile: International cooperation on Egypt's water crisis," EUROPEAN COUNCIL ON FOREIGN RELATIONS ecfr.eq, (2018).

[3] Shatat, Mahmoud, and Saffa B. Riffat. "Water desalination technologies utilizing conventional and renewable energy sources." International Journal of Low-Carbon Technologies 9, no. 1 (2014): 1-19. https://doi.org/10.1093/ijlct/cts025

[4] Osman, Rehab, Emanuele Ferrari, and Scott McDonald. "Water scarcity and irrigation efficiency in Egypt." Water Economics and Policy 2, no. 04 (2016): 1650009. https://doi.org/10.1142/S2382624X16500090

[5] Ministry of Water Resources and Irrigation, "Water Scarcity in Egypt: The Urgent Need for Regional Cooperation among the Nile Basin Countries," Minist. Water Resour. Irrig., no. water scaricity, pp. 1-4, 2014.

[6] Islam, M. S., A. Sultana, A. H. M. Saadat, M. Shammi, and M. K. Uddin. "Desalination technologies for developing countries: a review." Journal of Scientific Research 10, no. 1 (2018): 77-97. https://doi.org/10.3329/jsr.v10i1.33179

[7] Bennett, Anthony. "50th Anniversary: Desalination: 50 years of progress." Filtration+ Separation 50, no. 3 (2013): 32-39. https://doi.org/10.1016/S0015-1882(13)70128-9

[8] Bennett, Anthony. "50th Anniversary: Desalination: 50 years of progress." Filtration+ Separation 50, no. 3 (2013): 32-39.

[9] Lin, Hui-Wen, Rocío Cejudo-Marín, Adriaan W. Jeremiasse, Korneel Rabaey, Zhiguo Yuan, and Ilje Pikaar. "Direct anodic hydrochloric acid and cathodic caustic production during water electrolysis." Scientific reports 6 , no. 1 (2016): 1-4. https://doi.org/10.1038/srep20494

[10] Van der Bruggen, Bart. "Ion-exchange membrane systems-Electrodialysis and other electromembrane processes." In Fundamental Modelling of Membrane Systems, pp. 251-300. Elsevier, 2018. https://doi.org/10.1016/B978-0-12813483-2.00007-1

[11] Kumar, Amit, Katherine R. Phillips, Janny Cai, Uwe Schröder, and John H. Lienhard. "Integrated valorization of desalination brine through $\mathrm{NaOH}$ recovery: Opportunities and challenges." Angewandte Chemie 131, no. 20 (2019): 6570-6579. https://doi.org/10.1002/anie.201810469

[12] Andrew Griesmer, "What Is COMSOL Multiphysics?," COMSOL Multiphysics ${ }^{\circledR}, 2013$. [Online]. Available: https://www.comsol.com/blogs/what-is-comsol-multiphysics/. [Accessed: 06-Mar-2013].

[13] Fazlalia, Alireza, Vahab Ghaleh Khondabia, Arash Tayyebia, and Mostafa Keshavarz Moravejib. "CFD simulation of seawater desalination through a rectangular electrodialysis cell." Desalination and Water Treatment 1 (2018): 7. https://doi.org/10.5004/dwt.2019.23178

[14] Strathmann, Heiner. "Electrodialysis, a mature technology with a multitude of new applications." Desalination 264, no. 3 (2010): 268-288. https://doi.org/10.1016/i.desal.2010.04.069 
[15] Henrik Ekström, "How to Model Ion-Exchange Membranes and Donnan Potentials," COMSOL Multiphysics ${ }^{\circledR}, 2018$. [Online]. Available: https://www.comsol.com/blogs/how-to-model-ion-exchange-membranes-and-donnanpotentials/. [Accessed: 29-Aug-2018].

[16] Kwak, Rhokyun, Guofeng Guan, Weng Kung Peng, and Jongyoon Han. "Microscale electrodialysis: Concentration profiling and vortex visualization." Desalination 308 (2013): 138-146.

[17] El-Shafie, Omnia A., Rehab M. El-Maghraby, Jonathan Albo, Seif-Eddeen K. Fateen, and Amr Abdelghany. "Modeling and numerical investigation of the performance of gas diffusion electrodes for the electrochemical reduction of carbon dioxide to methanol." Industrial \& Engineering Chemistry Research 59, no. 47 (2020): 20929-20942. https://doi.org/10.1021/acs.iecr.0c02358

[18] Rahman, Musfika, and Iskandar Dzulkarnain. "Response Surface Method for Modelling the Effect of $\mathrm{CO}_{2}$ in Brine/Waxy Oil Interfacial Tension during LSW-WAG Enhanced Oil Recovery." Journal of Advanced Research in Applied Sciences and Engineering Technology 22, no. 1 (2021): 54-68. https://doi.org/10.37934/araset.22.1.5468 